\title{
Disinfection of Cystoscopes by Subatmospheric Steam and Steam and Formaldehyde at $80^{\circ} \mathrm{C}$
}

\author{
V. G. ALDER, J. C. GINGELL， J. P. MITCHELL
}

British Medical fournal, 1971, 3, 677-680

Summary

A new method of disinfection adapted for endoscopic instruments uses low temperature steam at $80^{\circ} \mathrm{C}$ or steam and formaldehyde at $80^{\circ} \mathrm{C}$. The process has considerable advantages over existing methods and more closely approaches the ideal requirements.

\section{Introduction}

The various methods of disinfection at present used for endoscopic instruments include immersion in an antiseptic solution (Miller et al., 1960), pasteurization in water (Francis, 1959), exposure to formalin vapour in a cabinet, and exposure to ethylene oxide. Though certain endoscopes are able to withstand autoclaving, this method cannot be used for all parts of the endoscope or for children's instruments. None of these methods combine a time cycle rapid enough for ready availability and at the same time allow for prepacking.

The use of low-temperature steam at $80^{\circ} \mathrm{C}$ was developed for the purpose of disinfecting heat-sensitive hospital equipment (Alder and Gillespie, 1961), and the method was first used for the disinfection of woollen blankets (Alder and Leitch, 1963). Since 1964 the use of steam only or steam with formaldehyde at $80^{\circ} \mathrm{C}$ has been successfully employed for the disinfection of endoscopic instruments in the United Bristol Hospitals (Mitchell, 1970; Mitchell and Alder, 1970) This paper describes the apparatus and the method of operating the disinfector. The bacteriological test methods developed in order to evaluate the efficiency of this new method of disinfection are discussed.

\section{Materials and Methods}

Low-temperature Steam and Formaldehyde Disinfection.-The principle of the method is based on the fact that if steam or a steam formaldehyde mixture is admitted to a previously evacuated chamber the temperature of the steam (being dependent on its pressure inside the chamber) can be accurately maintained by the simple process of controlling the pressure. Thus the optimum temperature required to obtain the maximum bactericidal effect with minimum damage to instruments was found to be $80^{\circ} \mathrm{C}$ (Fig. 1).

A diagram of the apparatus originally developed in Bristol is shown in Fig. 2. It was modified for low-temperature steam disinfection from a standard high-pressure autoclave. The apparatus consisted of a horizontal, rectangular, jacketed autoclave, 71 litres (2.5 cubic feet) capacity, to which was fitted a valve for controlling the steam pressure at $355 \mathrm{~mm} \mathrm{Hg}$, a formaldehyde generator, and a high-vacuum pump. The jacket temperature was maintained at $90^{\circ} \mathrm{C}$; while the chamber was maintained at $80^{\circ} \mathrm{C}$; there is no risk of damaging packaged instruments by superheat from the jacket during disinfection.

United Bristol Hospitals, Bristol BS2 8HW

V. G. ALDER, PH.D., M.R.C.PATH., Consultant Bacteriologist

J. C. GINGELL, M.B., P.R.C.S.(ENG., ED.), Senior Registrar in Urology

J. P. MITCHELL, M.S., F.R.C.S.(ENG., ED.), Consultant Urologist

Endoscopes.-The instruments used were of British, German, and American manufacture. Children's endoscopes, fibreilluminated telescopes, and cables were also subjected to the disinfecting process.

Packaged Method.-The endoscopes, complete with electric light bulbs, leads, and switches are packaged in layers of plastic foam shaped to the parts of the instrument and then enclosed in a cardboard box (Fig. 3). In this way, after disinfection, the instruments can be conveniently and safely stored for subsequent usage. The cardboard boxes themselves, when received from the manufacturers, should be subjected to a high-temperature autoclaving process $\left(134^{\circ} \mathrm{C}\right)$. This single treatment eliminates bituminous products from the cardboard, which might otherwise be deposited on the surface of the endoscopes.

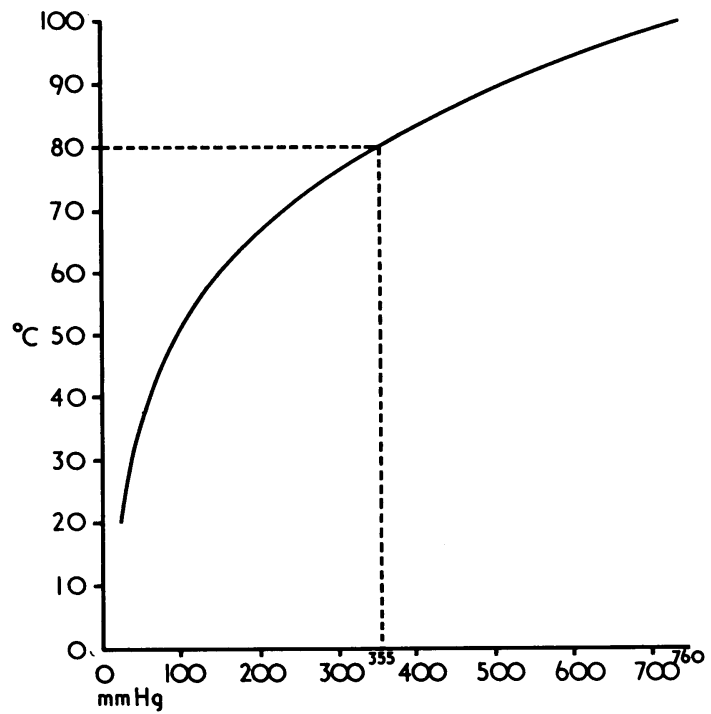

FIG. 1-Temperature of saturated steam at pressures below atmospheric.

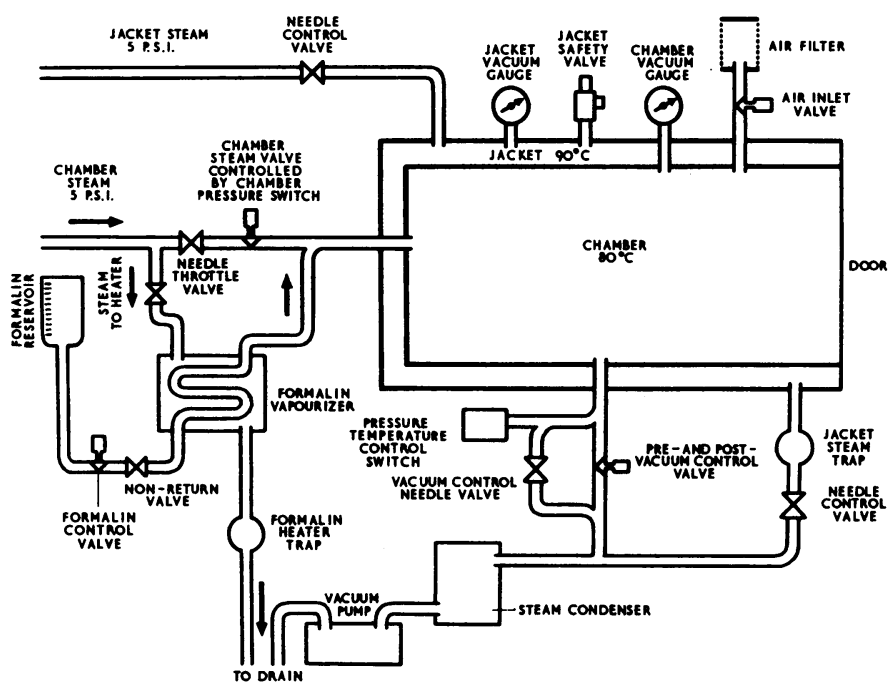

FIG. 2-Diagram of autoclave modified for use with subatmospheric steam and formaldehyde. 


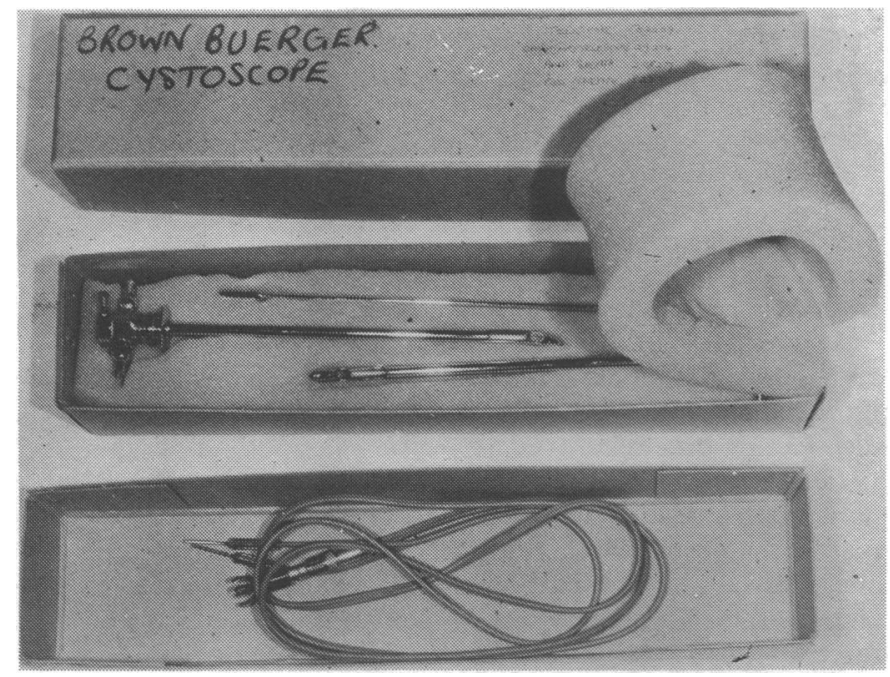

FIG. 3-Packaging of endoscopes for disinfection and storage.

Method of Operation for Steam and Formaldehyde at $80^{\circ} \mathrm{C}$.(1) Air is evacuated from the chamber to a final positive pressure of $12 \mathrm{~mm} \mathrm{Hg}$ or less. (2) Two millilitres of formalin per cubic foot of autoclave space is admitted to the chamber through the vaporizer and the chamber is then re-evacuated. This process is repeated twice more to remove traces of air and to ensure a thorough penetration of formaldehyde throughout. The process is known as "pulsing." (3) Eight millilitres of formalin per cubic foot of autoclave space is then passed through the vaporizer into the chamber and afterwards steam is admitted to a final pressure of $355 \mathrm{~mm} \mathrm{Hg} 80^{\circ} \mathrm{C}$ (approximately minus $380 \mathrm{~mm} \mathrm{Hg}$ ) and maintained for two hours. It is important to admit formaldehyde to the chamber before the steam in order to achieve a deep penetration of the gas. (4) After disinfection the chamber is evacuated by the high-vacuum pump to a final pressure of $15 \mathrm{~mm} \mathrm{Hg}$. (5) Filtered air is then admitted to the chamber to atmospheric pressure and the dry sterile packages are removed.

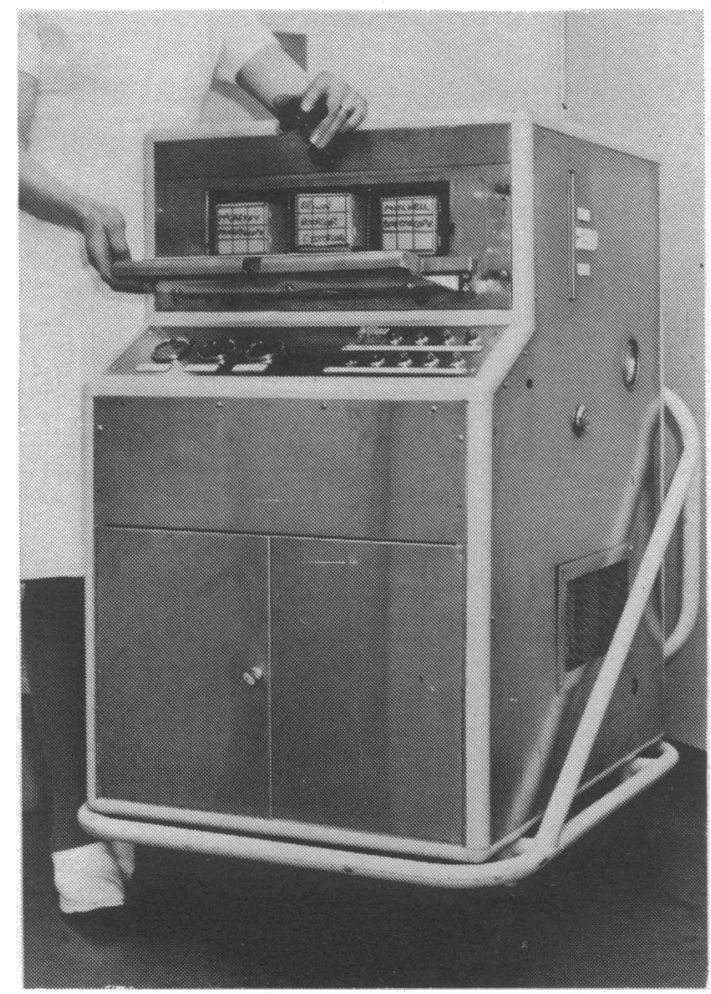

FIG. 4-Small transportable low-pressure steam disinfector loaded for use.
Method of Operation for Steam only at $80^{\circ} \mathrm{C}$. - The method of operating the autoclave for disinfection by steam only is similar to that for steam and formaldehyde, except that no formalin is used at any stage and the period of exposure to steam at $80^{\circ} \mathrm{C}$ is only five minutes. The full process takes about 15 minutes.

A small transportable sterilizing unit (designed by Drayton Castle Co. Ltd.) has been constructed for use in the operating theatre and takes three cystoscopes per cycle (Fig. 4). It requires only a cold water supply and a drain, being plugged into the mains electricity supply which heats a "built-in" steam generator. It operates automatically and has been working satisfactorily for the past five years in regular usage.

\section{BACTERIOLOGICAL METHODS}

Monitoring Test Pieces.-In order to evaluate the efficiency of the disinfection method for cystoscopes, it was necessary to test for bacterial survival in conditions likely to be found on the instrument. An attempt to solve this problem was made by constructing test pieces simulating the most protected areas of cystoscopes but which could be submitted fairly easily to bacteriological examination. One test piece consisted of a screw-capped chamber about $28 \mathrm{ml}$ capacity with a 7-inch $(17 \cdot 8-\mathrm{cm})$ length of $1-\mathrm{mm}$ bore tubing soldered into the lid. Fig. 5 illustrates the test piece, which was constructed from a standard laboratory glass Universal container. The steam

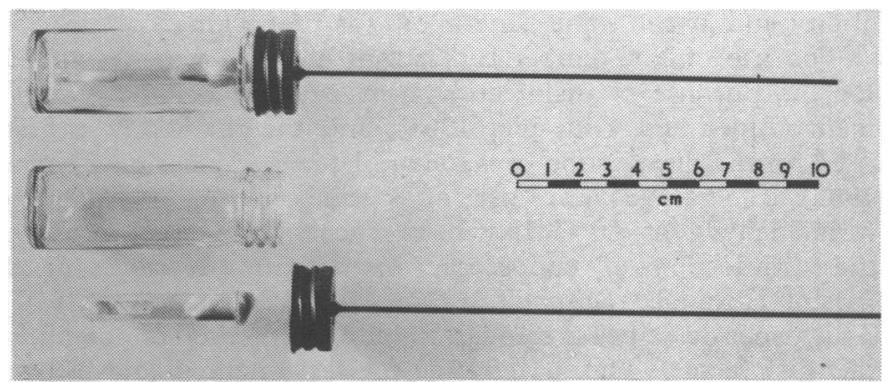

FIG. 5-Simulator test pieces, the upper one assembled with culture medium inserted for determining sterilizing efficiency.

and formaldehyde had to pass along the tubing to enter the chamber within which was placed cultures of bacteria in small plugged glass test-tubes. The test pieces vere sealed in paper bags and placed in cardboard cartons before exposure to steam or stean and formaldehyde. It was concluded that if the organisms were killed inside the test pieces one could be reasonably certain that they would be killed inside a cystoscope. In further tests to simulate conditions of interfacial surface contamination inside taps, the bacteria were smeared on the threads of a nut and bolt, which was then assembled, sealed inside a paper bag, and exposed to steam or steam and formaldehyde. The nut and bolt was afterwards unscrewed while still inside the paper bag, and then the two pieces were taken out and placed in culture media.

Test Organisms.-The routine test organisms used were Streptococcus faecalis and spore suspensions of Bacillus stearothermophilus. The cultures were dried in serum and saline on filter strips and placed in small glass tubes plugged with cotton-wool. B. stearothermophilus is a useful test organism for testing the efficiency of sterilizing by formaldehyde. The mature spores are quite resistant to heat at $80^{\circ} \mathrm{C}$ and therefore can be affected only by formaldehyde. Str. faecalis was used when disinfection by steam only was being carried out. In some special tests additional cultures of Staphylococcus aureus, Escherichia coli, and Pseudomonas aeruginosa were also used.

Culture Media.-Heart infusion nutrient broth was used for growing Str. faecalis which was incubated at $37^{\circ} \mathrm{C}$ for 
three days. Tryptone dextrose broth (Oxoid) was used for growing $B$. stearothermophilus which was incubated at $56^{\circ} \mathrm{C}$ for five days.

\section{Results}

Penetration of tubing and monitoring test pieces was achieved by low-temperature steam and formaldehyde and the test spore cultures were always killed within two hours. The process failed to kill spores on several occasions when they were entrapped between the threads of assembled nuts and bolts. All the non-sporing organisms were killed within five minutes by steam only at $80^{\circ} \mathrm{C}$, even when they were entrapped inside the threads of assembled nuts and bolts.

\section{Discussion}

To evaluate the efficiency of the disinfecting processes described, the problem of testing for bacterial survival in the more protected areas of the endoscopic instruments was overcome by the construction of monitoring test pieces or simulators. The use of such simulators has shown that both subatmospheric steam and steam and formaldehyde are bacteriologically safe methods of disinfection. Each method ensures the destruction of all vegetative cells on any part of the instrument. The limitations of using steam only at $80^{\circ} \mathrm{C}$ is that bacterial spores will survive the process, the addition of small amounts of formaldehyde vapour to the steam, however, converts it into a sporicidal process. Ideally, all bacteria on the endoscopes, including spores, should be destroyed, but in practice a method which gives guaranteed destruction of non-sporers can be accepted, since sporing bacteria rarely infect the urinary tract and their transmission by cystoscopes is unlikely (Association of Clinical Pathologists, 1967).

\section{IMMERSION IN FLUID DISINFECTANTS}

The method of low-pressure steam and formaldehyde disinfection of endoscopes at $80^{\circ} \mathrm{C}$ has a number of advantages compared with other disinfection methods. Immersion in fluid disinfectants is less reliable than heat methods and is entirely dependent on thorough cleaning of the instrument. Endoscopic instruments are difficult to clean thoroughly and there is a risk of damaging the lens mounting by too vigorous cleaning methods. There is also difficulty in cleaning the inside of the sheath and the crevices of metal junctions, particularly the interfacial metal surfaces inside taps. Organisms embedded in organic matter, such as coagulated serum or even dried urine, may be protected from the chemical disinfectant and survive the treatment. Air bubbles inside the sheath of the cystoscope may also prevent the sterilizing fluid from reaching the entire lumen of the instrument (Miller et al., 1960). The popular method of immersion in $0.5 \%$ chlorhexidine digluconate (Hibitane) in $70 \%$ ethanol for two minutes provides a rapid method of disinfection with the mentioned limitations but is damaging to the lens mounting. Aqueous chlorhexidine is less damaging but takes longer.

\section{EXPOSURE TO DISINFECTING VAPOURS}

Disinfection by enclosure in formalin vapour also has serious bactericidal limitations (Williams et al., 1966), and despite careful rinsing and wiping particles of formalin are retained on the surface and irritate the mucous membrane of the patient and conjunctivae of the operator. In addition, objections have been raised about the use of formaldehyde for sterilizing electrical equipment, as the breakdown products methanol and formic acid erode the electrical connexions (Opfell and
Miller, 1965). In contrast, after steam and formaldehyde disinfection at $80^{\circ} \mathrm{C}$ only minute quantities of formalin in the order of 4-8 parts per million remain on rubber and polyethylene (Gibson et al., 1968). On the metal of endoscopic instruments the quantities are neglible as there is no absorption of gases, and after numerous applications of steam and formaldehyde at $80^{\circ} \mathrm{C}$ the electrical connexions of the endoscopes have suffered no apparent damage.

Exposure to ethylene oxide gas, a method of sterilization extensively used in America, but of relatively limited acceptance in this country, is a method which also depends greatly on thorough cleansing of the instrument before exposure. There are also difficulties in controlling the critical level of humidity (Kelsey, 1961, 1963). In tests carried out by one of us (V.G.A.) to compare the speed of efficiency of ethylene oxide gas sterilization at $56^{\circ} \mathrm{C}$ for two hours, $B$. stearothermophilus spores dried from serum and saline suspensions survived after exposure to the gas, whereas similar spore culture preparations exposed to steam and formaldehyde gas at $80^{\circ} \mathrm{C}$ for two hours were consistently killed. Also in a two-hour exposure period ethylene oxide gas failed to kill vegetative cells entrapped between the threads of a nut and bolt, whereas sufficient heat from the steam at $80^{\circ} \mathrm{C}$ was conducted through the metal to kill the same organisms within five minutes. Exposure to ethylene oxide gas is not practical for routine purposes in the operating theatre during a cystoscopy list owing to the comparative slowness of the method. In a routine list of cystoscopies the same type of instrument can be used repeatedly if the method of sterilization is rapid enough.

\section{DISINFECTION BY HEAT}

The most effective method of sterilizing any instrument is by heat, but not all modern instruments can be subjected to autoclaving. Pasteurization, recommended by Francis (1959), is widely used and does not subject the telescope to the violent agitation from the bubbles of boiling water. The time cycle from dirty trolley to clean trolley (not less than 25 minutes in practice) is acceptable, but the instrument is wet and cannot be stored in a disinfected condition.

Ideally any method of sterilization for endoscopic instruments must be reliably bactericidal and avoid chemical or heat trauma to the instrument. The method should have a rapid time cycle and be standard for all parts of the instrument. Preferably it should allow prepacking of the instruments in a sterile state for safe storage, transport, and ready availability. It is an advantage if the method is economical and easy to operate and control.

Disinfection of endoscopic instruments by subatmospheric steam combines all of these advantages. We employ the longer steam and formaldehyde process because of its sporicidal properties for the disinfection of instruments at the end of an operating list. The apparatus is sited in the hospital group central steam sterilizing department, thus conforming to the modern principles of central sterilizing practices, and the instruments are prepacked in padded cardboard cartons, as described, allowing safe storage and transport in a dry sterile state. A small transportable automatic low-pressure steamsterilizing unit is installed in the theatre sterile supply unit to allow rapid disinfection of the prepacked instruments between cases.

Endoscopes have been processed routinely at the Bristol Royal Infirmary since 1964 in steam only at $80^{\circ} \mathrm{C}$ catering for five urological lists per week. Steam and formaldehyde disinfection has been used in addition in the scheme outlined since 1967. At first it was noticed that the lens mountings of endoscopes which had previously been immersed in chlorhexidine and $70 \%$ alcohol were damaged after exposure to the steam. After repair, however, the lens mountings have withstood the disinfection processes satisfactorily. 
Further reduction in the tempeature to $65-70^{\circ} \mathrm{C}$ (about $200 \mathrm{~mm} \mathrm{Hg}$ ) has been investigated. The destruction of all vegetative bacteria has been achieved, and though this further reduction in tempeature is not essential for cystoscopes it may prove to be of value for other heat-sensitive surgical instruments.

We gratefully acknowledge the help and advice received from Professor W. A. Gillespie, professor of clinical bacteriology, Bristol University, Dr. J. C. Kelsey, director of Sterilization and Disinfection Reference Laboratory, Central Public Health Laboratories, London, and Mr. A. Bishop, of the Department of Health and Social Security, London.

The transportable low-pressure steam sterilizing unit was built by Drayton Cartle Co. Ltd. with a development grant awarded by the Department of Health and Social Security, London.

\section{References}

Association of Clinical Pathologists (1967). Notes on Sterilization No. 1 , "Sterilization and Disinfection of Cystoscopes." London.

Alder, V. G., and Gillespie, W. A. (1961). Fournal of Clinical Pathology, 14,515 .

Alder, V. G., and Leitch, C. W. (1963). Hospital (London), 59, 662.

Francis, A. E. (1959). Proceedings of the Royal Society of Medicine, 52 , 998.

Gibson, G. L., Johnston, H. P., and Turkington, V. E. (1968). fournal of Clinical Pathology, 21, 771 .

Kelsey, J. C. (1961). Fournal of Clinical Pathology, 14, 59.

Kelsey, J. C. (1963). Fournal of Clinical Pathology, 16, 542

Miller, A., Gillespie, W. A., Linton, K. B., Slade, N., and Mitchell, J. P. (1960). Lancet, 2, 86.

Mitchell, J. P. (1970). British Medical fournal, 3, 241.

Mitchell, J. P., and Alder, V. G. (1970). British Hospital fournal, 80, 1944

Opfell, J. B., and Miller, C. B. (1965). Advances in Applied Microbiology, vol, 7 . New York, Academic Press.

Williams, R. E. O., Blowers, R., Garrod, L. P., and Shooter, L. P. (1966). Hospital Infection, 2nd edn. London, Lloyd-Luke.

\section{PRELIMINARY COMMUNICATIONS}

\section{Methylene Blue for Rapid Identification of the Parathyroids}

\section{N. E. DUDLEY}

British Medical fournal, 1971, 3, 680-681

\section{Summary}

Rapid identification of parathyroid tissue has been rendered possible by preoperative intravenous infusion of methylene blue before exploration of the neck. The technique has been used on 17 patients with thyroid and parathyroid disorders. In all cases one or more of the parathyroids have been demonstrated with histological confirmation, but with greater experience almost all have been shown readily. This has resulted in an appreciable reduction in operating time, and the method should help to reduce the high incidence of clinical hypoparathyroidism after total thyroidectomy.

\section{Introduction}

Selective in-vivo staining of the parathyroid glands by intravenous and intra-arterial administration of toluidine blue was first described in dogs (Klopper and Moe, 1966; Hurvitz et al., 1967) and later in rats and man (Hurvitz et al., 1968; Keaveny and FitzGerald, 1968; Keaveny et al., 1969; Yeager and Krementz, 1969). The enthusiasm of these workers and others (Professor Volker Bay, personal communication, 1970) encouraged me to attempt this method to avoid the frustration of prolonged searching for parathyroid adenomata. The withdrawal of toluidine blue from general use led to a search for an alternative dyestuff.

Experience in patients treated in this centre for methaemoglobinaemia with methylene blue suggested that this dye might be a reasonable and safe substitute, and this expectation has been fulfilled.

\section{Patients and Method}

Methylthionine chloride: tetramethylthionine chloride (methylene blue injection $1 \%$, Harvey Laboratories, Philadelphia) was administered at a calculated dose of $5 \mathrm{mg} / \mathrm{kg}$ body weight in $500 \mathrm{ml}$ of $5 \%$ glucose and $1 / 5$ normal saline. This volume of solution was found to give maximal staining of the parathyroids when infused intravenously for one hour before exposure of the neck. Seven patients with a variety of thyroid disorders, nine with suspected parathyroid tumours, and one with parathyroid hyperplasia were investigated. Where parathyroid adenomata were suspected exploration of the neck was carried out systematically in a manner similar to that proposed by Cope (1941). In the control group with thyroid disease, where surgery was sometimes difficult, it was not always considered justifiable to prolong the search for the parathyroids if they were not immediately obvious. Identification of all stained glands was verified by biopsy and immediate frozen section and later by paraffin block histological examination. Blood pressure, pulse, respiration, temperature, and E.C.G. were recorded before, during, and after operation. Serum calcium levels were measured before surgery and one week postoperatively to confirm that no adenomata had been missed or that any patient had been rendered hypoparathyroid.

\section{Results}

Intravenous administration of methylene blue resulted in staining of both normal and abnormal parathyroid glands. The total experience would seem at first to indicate that the method might not be helpful in that 68 parathyroid glands were looked for and $\mathbf{4 1}$ found and confirmed. However, the Table shows that experience of the technique and better timing of the infusion led to a progressive improvement in identification. All patients who were considered on clinical and biochemical grounds to have an adenoma had one readily displayed by this technique. The nine instances of adenomata were identified and confirmed histologically within 30 minutes of exposure compared with a previous mean of two hours before the adoption of this technique. In the last six cases as set out in the Table it will be seen that the identification of the glands became much simpler. In Case 13 a very large adenoma was found which had probably caused a pronounced hypoplasia of the remaining glands.

I have found that the colour of the parathyroids progressively increases in intensity after infusion of the dye up to one hour and seems to last for 20 minutes before diminishing in intensity over the next two and a half hours. The normal parathyroids 